\title{
Fluorescence Anisotropy and Rotational Diffusion of Two Kinds of 4-n-alkyl-4'-cyanobiphenyls in Glycerol
}

\author{
Hideyo Matsuzawa*, Kentaro Watanabe and Makio Iwahashi \\ Department of Chemistry, School of Science, Kitasato University (1-15-1 Kitasato, Sagamihara, Kanagawa-ken, 228-8555, JAPAN)
}

\begin{abstract}
Absorption and fluorescence spectra, fluorescence lifetimes, and steady-state and time-resolved fluorescence anisotropies were measured for 4-methyl-4'-cynanobiphenyl (1CB) and 4-hexyl-4'cynanobiphenyl $(6 \mathrm{CB})$ in glycerol at various temperatures. The energies and intensities of the absorption and emission spectra for $1 \mathrm{CB}$ and $6 \mathrm{CB}$ were almost equally observed, and the fluorescence lifetimes around 1.0 ns were also almost equally obtained and did not depend on temperature. However, the timeresolved fluorescence anisotropies measured in glycerol solution indicated that the molecules of $1 \mathrm{CB}$ rotate more rapidly than those of $6 \mathrm{CB}$ : the rigid-sphere radii for $1 \mathrm{CB}$ and $6 \mathrm{CB}$ obtained by using the pulsed exciting light were evaluated as $1.3 \times 10^{-10} \mathrm{~m}(1 \mathrm{CB})$ and $1.8 \times 10^{-10} \mathrm{~m}(6 \mathrm{CB})$ in the low temperature region $\left(2-10{ }^{\circ} \mathrm{C}\right)$, whereas those evaluated in the high temperature regions $\left(20-60^{\circ} \mathrm{C}\right.$ for $1 \mathrm{CB}$ and $30-60$ for $\left.6 \mathrm{CB}\right)$ were $2.7 \times 10^{-10} \mathrm{~m}(1 \mathrm{CB})$ and $3.6 \times 10^{-10} \mathrm{~m}(6 \mathrm{CB})$. These radii evaluated in the high temperature region were in good agreement with those obtained by using steady-state exciting light, $2.9 \times 10^{-10} \mathrm{~m}(1 \mathrm{CB})$ and $3.4 \times 10^{-10} \mathrm{~m}(6 \mathrm{CB})$. It is noted that the increase of radius was observed across an intermediate temperature region $\left(10-30{ }^{\circ} \mathrm{C}\right.$ for $1 \mathrm{CB}$ or $10-40^{\circ} \mathrm{C}$ for $\left.6 \mathrm{CB}\right)$, and was more remarkable for $6 \mathrm{CB}$ than for 1CB. This implies that the movements of hexyl-chain are much more enhanced at high temperature, and are effectively reflected to the increase in radius of rotational diffusion. The changing phenomenon of movements of peripheral alkyl-chain in liquid-crystal molecules is important for the phase transition between liquid crystal and isotropic liquid phases: the changing to less vigorous movements of the alkylchain in $6 \mathrm{CB}$ is thought enough to contribute to the liquid-crystal formation of $6 \mathrm{CB}$ molecule.
\end{abstract}

Key words: liquid crystal, 4-n-alkyl-4'-cyanobiphenyl, 4-methy-4'-cyanobiphenyl, 4-hexyl-4'-cyanobiphenyl, fluorescence anisotropy, fluorescence decay time

\section{INTRODUCTION}

4- $n$-Alkyl-4'-cyanobiphenyls ( $n \mathrm{CB}, n$ is the carbon number in an alkyl chain) are known to make thermotropic liquid crystals and broadly used as display materials. Lydon and Coakley ${ }^{1)}$ reported that $8 \mathrm{CB}$ in its smectic liquid crystal phase has a lamellar structure and that the thickness of the lamellar layer is $29.2 \pm 0.3 \times 10^{-10} \mathrm{~m}: 8 \mathrm{CB}$ molecules in the lamellar layer are thought to interpenetrate one another. Consequently, there would be interactions between alkyl chains and/or a stacking of biphenyl groups. 7CB in its liquid and/or nematic liquid crystal phase has a similar structure to that of $8 \mathrm{CB}^{2)}$. NMR and IR results ${ }^{3,5)}$ in the phase transition temperature regions suggest that the cyanobiphenyl and alkyl parts differently contribute to the formation of liquid crystal: relatively rigid biphenyl part in 4 - $n$-alkyl-4'-cyanobiphenyl molecule largely contributes to the formation of liquid crystal phase, while flexible alkyl part also contributes to the formation of liquid crystal phase and to the determination of the type of the liquid crystal phases.

However, the real dynamical molecular structures of the 4- $n$-alkyl-4'-cyanobiphenyls in their liquid and also in their liquid-crystal phases are still under a dark screen, although the molecules of the 4-n-alkyl-4'-cyanobiphenyls are thought to move vigorously in their liquid and even in their liquid-crystal phase.

*Correspondence to: Hideyo Matsuzawa, Department of Chemistry, School of Science, Kitasato University, 1-15-1 Kitasato, Sagamihara, Kanagawa-ken 228-8555, JAPAN

E-mail: matsu@sci.kitasato-u.ac.jp

Accepted July 23, 2007 (recieved for review June 11, 2007)

Journal of Oleo Science ISSN 1345-8957 print / ISSN 1347-3352 online

http://jos.jstage.jst.go.jp/en/ 


\section{H. Matsuzawa, K. Watanabe and M. Iwahashi}

The assembly structure of the molecules is important for the formation of the liquid crystal phase. Furthermore, for understanding the assembly structure of the liquid crystal, it is also essential to know the contributions of the alkyl and cyanobiphenyl parts to the movements of cyanobiphenyl molecule.

The situation of the $\pi$-electrons in the cyanobiphenyl part is thought to be unaffected by the alkyl part in the very dilute solution, where the $n \mathrm{CB}$ molecules do not approach each other in its excitation lifetime. In a concentrated condition, however, even in an isolated molecular situation, cyanobiphenyl part would be influenced by alkyl parts.

In general, the fluorescence emitted from molecules which are dispersed in viscous medium is partially polarized. This is customarily expressed in terms of molecular anisotropy, $\bar{r}$, which is measured at right angle to a polarized excitation beam.

In the present study, in order to know the contribution of the alkyl group to the formation of the liquid crystal phase, we studied the dynamical properties such as rotational diffusion (rotational movement) and dynamical molecular volume for $1 \mathrm{CB}$ and $6 \mathrm{CB}$ in dilute glycerol solution through the measurements of fluorescence lifetimes, and steadystate and time-resolved fluorescence anisotropies. In this study, we chose $6 \mathrm{CB}$, as a typical 4 - $n$-alkyl-4'cyanobiphenyl, which forms a nematic liquid crystal, and $1 \mathrm{CB}$ which does not form liquid crystal.

\section{EXPERIMENTAL}

\subsection{Materials}

Sample of 1CB (Merck, 99.6\% pure) was purified by twice-recrystallization from hexane. Samples of $6 \mathrm{CB}$ (Merck, 99.6\%) and glycerol (Kanto Kagaku Co. Ltd, analytical grade sample for fluorescence measurements), which is used as a viscosity changeable solvent, were used without further purification. All the samples for fluorescence measurements, and also for the fluorescence decay-time measurements, were prepared after de-oxygen by bubbling with $\mathrm{N}_{2}$ gas. Typical concentrations of sample for the measurements were dilute $\left(\sim 5 \times 10^{-5} \mathrm{moldm}^{-3}\right)$ enough to avoid the formation of association of $n \mathrm{CB}$ molecules in the ground and the excited states.

\subsection{Optical measurements (method and apparatus)}

Absorption spectra were measured on a Hitachi U-3210 spectrophotometer. Fluorescence spectra and steady-state fluorescence anisotropy, $\bar{r}$, were measured at right angle relative to the exciting beam with a Hitachi 850 spectrofluorometer. To prevent the scattering light interfering the fluorescence measurements, sharp-cut filters (UV29, 31) equipped in the instrument were used. All the optical mea- surements were carried out under the temperature condition regulated within $\pm 0.1^{\circ} \mathrm{C}$ using a water-circulating temperature controller (CTE-32, Yamato Science Instruments Co. Ltd.). Non-fluorescence-four-faced quartz cells having $1 \mathrm{~cm}$ light-path length were used for all fluorescence measurements.

\subsection{Steady-state fluorescence anisotropy, $\bar{r}$}

When a vertical (horizontal) polarizer is installed in the excitation part of the instrument, the steady-state fluorescence anisotropy, $\bar{r}$, is defined as:

$$
\bar{r}=\frac{I_{V V}-I_{V H}}{I_{V V}+2 I_{V H}}
$$

where $I_{\mathrm{VV}}$ and $I_{\mathrm{VH}}$ are the fluorescence intensities observed through a polarizer oriented perpendicular and parallel to the plane of polarization of the excitation beam. The first and the second sub-symbols of $I$ mean the directions of the polarizing planes of the excitation part and of the emission part, respectively. Since the polarizers used in the instrument have a characteristic property in the polarization, we should consider the instrument constant for getting exact results. Thus, equation 1 becomes as follows:

$$
\bar{r}=\frac{I_{V V}-G I_{V H}}{I_{V V}+2 G I_{V H}}
$$

In this equation, $G$ is a correction factor for detection system, which is expressed as the ratio of sensitivities of the detection system for vertically and horizontally polarized light; $G$ is obtained by

$$
G=\frac{I_{H V}}{I_{H H}}
$$

where $I_{\mathrm{HV}}$ and $I_{\mathrm{HH}}$ are the fluorescence intensities polarized perpendicular and parallel components when the excitation beam is horizontally polarized. From equations 2 and 3, we obtain the following Azumi-McGlynn equation ${ }^{6)}$ :

$$
\bar{r}=\frac{I_{V V} I_{H H}-I_{V H} I_{H V}}{I_{V V} I_{H H}+2 I_{V H} I_{H V}}
$$

We used a Hitachi polarizer unit (650-142) as the polarizers for determining the intensities of $I_{\mathrm{Vv}}, I_{\mathrm{HH}}, I_{\mathrm{VH}}$ and $I_{\mathrm{HV}}$.

\subsection{Fluorescence decay time}

Fluorescence decay time was measured on a Horiba NAES-700 time-resolution photoluminescence fluorometer, using a pulsed light source composed of high pressure hydrogen lamp. A band-path filter (Hoya U-340) and a solution filter $\left(0.500 \mathrm{kgdm}^{-3} \mathrm{NiSO}_{4}\right)$ were used for the selection of the exciting light beam and a sharp-cut filter (Hoya L-40) 
was used for preventing scattering light which interfere the fluorescence measurements. The temperature during the measurements was controlled within $\pm 0.1^{\circ} \mathrm{C}$ with a low temperature controller (LCH-111 Labothermo Cool, Advantec Co. Ltd.).

\subsection{Time-resolved fluorescence anisotropy, $r(t)$}

The time-resolved fluorescence anisotropy, $r(t)$, to be measured is given by

$$
r(t)=\frac{I_{V V}(t)-I_{V H}(t) G}{I_{V V}(t)+2 I_{V H}(t) G}
$$

and

$$
G=\frac{\int_{0}^{t} I_{H V}(t) d t}{\int_{0}^{t} I_{H H}(t) d t}
$$

where $I_{\mathrm{VV}}(t)$ and $I_{\mathrm{VH}}(t)$ denote the fluorescence intensities of the sample measured with a polarization analyzer perpendicular and parallel, respectively, with respect to the electrical vector of the exciting light which is vertically polarized; $G$ is the correction factor owing to the difference of the sensitivities of the detector to the vertically polarized and horizontally polarized lights.

\section{RESULTS AND DISCUSSION}

\subsection{Absorption and fluorescence spectra}

Figure 1 shows absorption and fluorescence spectra for $1 \mathrm{CB}$ and $6 \mathrm{CB}$ in glycerol at $20.3^{\circ} \mathrm{C}$. $1 \mathrm{CB}$ and $6 \mathrm{CB}$ exhibit absorption bands having a peak at $35 \times 10^{3} \mathrm{~cm}^{-1}$, which is

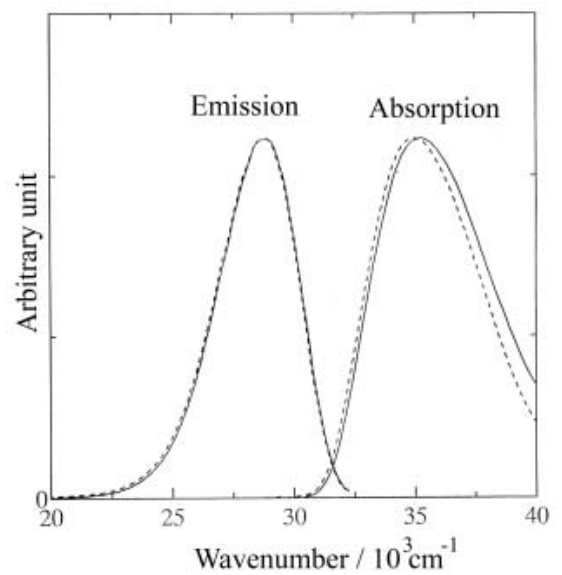

Fig. 1 Absorption and Emission Spectra for $1 \mathrm{CB}$ and $6 \mathrm{CB}$ in Glycerol at $20.3^{\circ} \mathrm{C}$.

Solid line expresses $1 \mathrm{CB}$ and dashed line $6 \mathrm{CB}$, respectively. assigned to $\left(\pi, \pi^{*}\right)$ transition of $\pi$-electron system of their cyanobiphenyl groups; they also emit fluorescence around $29 \times 10^{3} \mathrm{~cm}^{-1}$. The peak positions and the profiles of the absorption and fluorescence bands for $6 \mathrm{CB}$ are almost the same as those for $1 \mathrm{CB}$. This indicates that the absorption and emission processes for the cyanobiphenyls are not influenced by the length of the alkyl chain attached to the cyanobiphenyl group.

\subsection{Fluorescence decay time (Excited-state lifetime)}

Figure 2 shows the convoluted fluorescence decay curve for $1 \mathrm{CB}$ in glycerol at $10.1^{\circ} \mathrm{C}$. For comparison, the decay profile of hydrogen lamp source is also presented with a dashed and pointed line. Beyond the peak top of the fluorescence decay curve, decreasing curve is seen in the semi-log plot of intensity against time. The fluorescence lifetime can be obtained by the application of following equation to the observed decay curve:

$$
\ln I(t)=\ln A_{1}-\frac{1}{\tau} t
$$

where $I(t)$ is the intensity of fluorescence at an arbitrary time $t, A_{1}$ is the initial fluorescence intensity and $\tau$ is the fluorescence lifetime for the sample. Actually, the decay profile of the lamp source influences the sample decay, and hence, the corrected lifetimes were calculated by the deconvolution method using least-squares fitting for the observed decay curves. Thus we obtained 998 ps (standard deviation, S.D. $\left.=24.5 \mathrm{ps} ; \chi^{2}=1.25\right)$ as the lifetime of $1 \mathrm{CB}$ at $10.1^{\circ} \mathrm{C}$. Similarly, the values of $\tau$ for the $1 \mathrm{CB}$ and $6 \mathrm{CB}$ at

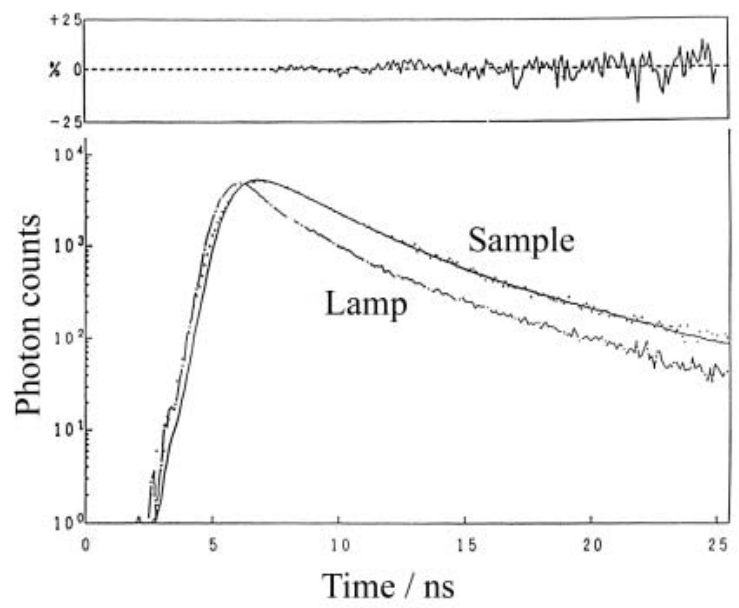

Fig. 2 Fluorescence Decay Curve (solid line) for $1 \mathrm{CB}$ in Glycerol at $10.1{ }^{\circ} \mathrm{C}$.

Dashed and pointed line denotes light source. The lifetime was calculated as 998 ps (S.D. $=24.5$ ps, $\chi^{2}$ $=1.25)$. The upper part of figure shows the residuals of the observed and the calculated values. 
Table 1 Fluorescence Lifetimes, $\tau$, of $1 \mathrm{CB}$ and $6 \mathrm{CB}$ in Glycerol at Various Temperatures. (S.D.: standard deviation)

\begin{tabular}{|c|c|c|c|}
\hline \multicolumn{2}{|c|}{$1 \mathrm{CB}$} & \multicolumn{2}{c|}{$6 \mathrm{CB}$} \\
\hline Temperature $/{ }^{\circ} \mathrm{C}$ & $\tau /$ ns (S.D.) & Temperature $/{ }^{\circ} \mathrm{C}$ & $\tau /$ ns (S. D.) \\
\hline 3.4 & $1.03(0.026)$ & 1.5 & $1.03(0.026)$ \\
\hline 10.1 & $0.99(0.025)$ & 10.1 & $0.99(0.025)$ \\
\hline 20.3 & $1.03(0.022)$ & 20.3 & $1.03(0.012)$ \\
\hline 30.4 & $1.06(0.012)$ & 30.2 & $1.06(0.012)$ \\
\hline 40.7 & $1.02(0.012)$ & 40.9 & $1.02(0.012)$ \\
\hline 50.6 & $1.00(0.016)$ & 50.7 & $1.00(0.016)$ \\
\hline 60.8 & $0.98(0.013)$ & & \\
\hline
\end{tabular}

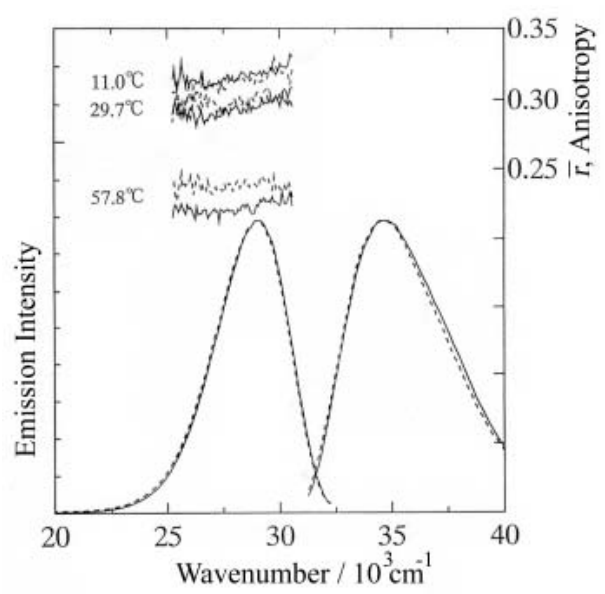

Fig. 3 Emission and Excitation Spectra for $1 \mathrm{CB}$ and $6 \mathrm{CB}$ in Glycerol at $11.0^{\circ} \mathrm{C}$, and Their Fluorescence Anisotropies at Various Temperatures.

Solid line denotes $1 \mathrm{CB}$ and dotted line, 6CB.

various temperatures were determined and are listed in Table 1. It is worth noting that the fluorescence lifetimes are about $1 \mathrm{~ns}$ for both $1 \mathrm{CB}$ and $6 \mathrm{CB}$ and are independent of temperature.

\subsection{Steady-state fluorescence anisotropy, $\bar{r}$}

Figure 3 shows the fluorescence excitation and emission spectra for $1 \mathrm{CB}$ and $6 \mathrm{CB}$ in glycerol. The fluorescence spectra of $n \mathrm{CB}$ were measured by using the excitation light having $285 \mathrm{~nm}$ wavelength $\left(35.0 \times 10^{3} \mathrm{~cm}^{-1}\right)$. As the viscosity of the glycerol decreases exponentially with increasing temperature ${ }^{9)}$, it is possible to change the viscosity condition for $n$-cyanobiphenyls by using glycerol as a solvent for the observation of the steady-state fluorescence anisotropy, $\bar{r}$. Thus, we observed the $\bar{r}$ values for $1 \mathrm{CB}$ and $6 \mathrm{CB}$ in glycerol at various temperatures.

First of all, in order to determine the relative directions of the transition moments of absorption and fluorescence
Table 2 Steady-state Fluorescence Anisotropy, $\bar{r}$, for 1CB and $6 \mathrm{CB}$ in Glycerol at Various Temperatures.

\begin{tabular}{|c|c|c|}
\hline Temperature $/{ }^{\circ} \mathrm{C}$ & $\bar{r}$ for $1 \mathrm{CB}$ & $\bar{r}$ for $6 \mathrm{CB}$ \\
\hline 11.0 & 0.318 & 0.315 \\
\hline 20.3 & 0.313 & 0.309 \\
\hline 29.7 & 0.299 & 0.296 \\
\hline 39.1 & 0.301 & 0.294 \\
\hline 48.4 & 0.242 & 0.267 \\
\hline 57.8 & 0.224 & 0.242 \\
\hline
\end{tabular}

oscillators in the lowest excited states of the cyanobiphenyl parts for $1 \mathrm{CB}$ and $6 \mathrm{CB}$, steady-state fluorescence anisotropy, $\bar{r}$, was determined in high viscous glycerol at $11^{\circ} \mathrm{C}$ (its viscosity is $\sim 4 \mathrm{~Pa} \mathrm{~s}$ ), where the rotational movements for the molecules of $1 \mathrm{CB}$ and $6 \mathrm{CB}$ are thought to be sufficiently low.

In the upper left in Fig. $3, \bar{r}$, values for $1 \mathrm{CB}$ at various temperatures are represented by solid lines and those for $6 \mathrm{CB}$ by dashed lines, respectively. The $\bar{r}$ value for $1 \mathrm{CB}$ is 0.318 and that for $6 \mathrm{CB}$ is 0.315 at $11^{\circ} \mathrm{C}$. These values are much higher than 0.1 and close to 0.4. In general, in the viscous medium where the molecules do not move within the fluorescence lifetime, $\bar{r}$ value takes the region of -0.2 $\bar{r}<0.4$. Namely, when the directions of the linear oscillators for the absorption and the emission are parallel to each other, $\bar{r}$ is 0.4 ; when those are perpendicular to each other, $\bar{r}$ is -0.2 ; and when the two planar oscillators for the absorption and the emission are parallel, $\bar{r}$ is $0.1^{7,8)}$. This criterion leads to the conclusion that the emission oscillators of the cyanobiphenyl molecules are parallel to the oscillator of absorption. In addition, it has been clarified on the basis of molecular orbital calculations (Matsuzawa, H., unpublished data) that the lowest intense absorption band around $35.0 \times 10^{3} \mathrm{~cm}^{-1}$ observed in cyanobi- 
phenyl molecules is assigned to ${ }^{1} \mathrm{~A}_{1}$ state (in $\mathrm{C}_{2 \mathrm{v}}$ symmetry) and its transition moment is directed along the long axis of the cyanobiphenyl molecule.

If the $n$-cynanobiphenyl molecules rotate perpendicularly against the long axis of the molecules during the fluorescence lifetime, the change in $\bar{r}$ should be observed. Table 2 shows the $\bar{r}$ values in glycerol at various temperatures. Increase in temperature decreases $\bar{r}$ values for both $1 \mathrm{CB}$ and $6 \mathrm{CB}$. Namely, the rotational movements of the molecules of $1 \mathrm{CB}$ and $6 \mathrm{CB}$ simply increase with increasing temperature upto $39^{\circ} \mathrm{C}$; in the higher temperature region, $1 \mathrm{CB}$ having small methyl group rotates in glycerol more vigorously than $6 \mathrm{CB}$ having a long alkyl chain.

The steady-state fluorescence anisotropy measurements, however, can not indicate the detail for the difference between the rates of rotations of the $1 \mathrm{CB}$ and $6 \mathrm{CB}$ molecules. Thus, the rates of rotations of the $1 \mathrm{CB}$ and $6 \mathrm{CB}$ molecules will be discussed in the section of time-resolved fluorescence anisotropy. Before mentioning the timeresolved fluorescence anisotropy, we now discuss the effective molar volumes for $1 \mathrm{CB}$ and $6 \mathrm{CB}$, which can be obtained from the $\bar{r}$ values and viscosities of glycerol at various temperatures.

\subsection{Effective molar volume}

By assuming that the molecules of $1 \mathrm{CB}$ and $6 \mathrm{CB}$ are rigid spheres, the following equation is applicable to the relation between the effective molar volume, $v$, and steadystate fluorescence anisotropy, $\bar{r}^{2}$ :

$$
\frac{1}{\bar{r}}=\frac{1}{\bar{r}_{0}}\left(1+\frac{k_{B} T \tau}{v \eta}\right)
$$

where $\bar{r}_{0}$ is steady-state fluorescence anisotropy under the condition that the viscosity, $\eta$, is infinity ; $k_{\mathrm{B}}$ is the Boltzmann constant. If the $\frac{1}{\bar{r}}$ versus $\frac{T}{\eta}$ plot (the Perrin-Weber plot) gives a straight line, the $v$ value should be obtained from the slope of the line and the fluorescence lifetime, $\tau$.

Figure 4 shows the Perrin-Weber plot for $1 \mathrm{CB}$ and $6 \mathrm{CB}$. Relatively good straight lines are obtained for both cyanobiphenyls. From the intercepts on $\frac{1}{\bar{r}}$ axis and slopes of the straight lines, we obtained $\bar{r}_{0}$ and $v$ values for $1 \mathrm{CB}$ and $6 \mathrm{CB}$, respectively. The values are 0.321 for $1 \mathrm{CB}$ and 0.315 for $6 \mathrm{CB}$; the $\mathrm{v}$ values are $1.06 \times 10^{-28} \mathrm{~m}^{3}$ for $1 \mathrm{CB}$ and $1.61 \times 10^{-28} \mathrm{~m}^{3}$ for $6 \mathrm{CB}$. Assuming rigid spheres for both $1 \mathrm{CB}$ and $6 \mathrm{CB}$ molecules, we obtained $2.94 \times 10^{-10} \mathrm{~m}$ for the molecular radius of $1 \mathrm{CB}$ and $3.37 \times 10^{-10} \mathrm{~m}$ for that of $6 \mathrm{CB}$, respectively: the rotating $6 \mathrm{CB}$ molecule is larger than the rotating $1 \mathrm{CB}$ molecule.

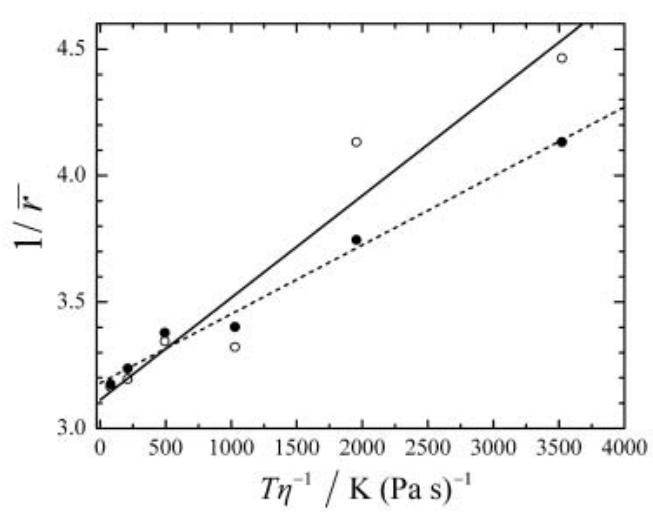

Fig. 4 Perrin-Weber Plots for $1 \mathrm{CB}$ and $6 \mathrm{CB}$ in Glycerol. Open circles denote $1 \mathrm{CB}$ and closed circles, $6 \mathrm{CB}$, respectively.

\subsection{Time-resolved fluorescence anisotropy, $r^{*}(t)$}

$I_{\mathrm{VV}}(t), I_{\mathrm{VH}}(t), I_{\mathrm{HV}}(t)$ and $I_{\mathrm{HH}}(t)$ in equation 5 were measured for $1 \mathrm{CB}$ and $6 \mathrm{CB}$ in glycerol at various temperatures. For the determination of the real fluorescence intensities of the samples, however, the convoluted waves, $I_{\mathrm{D}}(\mathrm{t})$ and $I_{\mathrm{T}}(\mathrm{t})$, are necessary instead of the difference in fluorescent intensities $\left(I_{\mathrm{VV}}(t)-I_{\mathrm{VH}}(t) G\right)$ and the overall fluorescence intensity $\left(I_{\mathrm{VV}}(t)+2 I_{\mathrm{VH}}(t) G\right)$ in equation 5 . This is because the intensities of $I_{\mathrm{VV}}(t)$ and $I_{\mathrm{VH}}(t)$ include the effect of spreading of the light source. Thus, first of all, we assume that $I_{\mathrm{D}}(t)$ and $I_{\mathrm{T}}(t)$ are expressed as the following exponential functions.

$$
\begin{aligned}
& I_{D}(t)=A_{D} \exp \left(-\frac{t}{\tau_{D}}\right) \\
& I_{T}(t)=A_{T} \exp \left(-\frac{t}{\tau_{T}}\right)
\end{aligned}
$$

$I_{\mathrm{D}}(t)$ and $I_{\mathrm{T}}(t)$ calculated using the convoluted $I_{\mathrm{VV}}(t), I_{\mathrm{VH}}(t)$, $I_{\mathrm{HV}}(t)$ and $I_{\mathrm{HH}}(t)$ values for $1 \mathrm{CB}$ and $6 \mathrm{CB}$ in glycerol were plotted in the semi-log scale against time, $t$.

For example, Fig. 5 and 6 show the decay curves of $I_{\mathrm{D}}(t)$ and $I_{\mathrm{T}}(t)$ at $50.6^{\circ} \mathrm{C}$ obtained for $1 \mathrm{CB}$ and $6 \mathrm{CB}$, respectively, which are relatively linear beyond their peak tops. Thus, the assumption that the $I_{\mathrm{D}}(t)$ and $I_{\mathrm{T}}(t)$ are expressed as the exponential functions of time, $t$, seems to be reasonable. Strictly speaking, the curves are composed of two components. However, the ratio of one component, having a short lifetime, to total curve is about $90 \%$, while the ratio of second component, having a long lifetime, to the total curve is less than $10 \%$. Thus the analysis was carried out only for the former component. The fluorescence anisotropy, $r^{*}(t)$, which suffers no effect from the spreading of the light source, is expressed as Eq. 11.

$$
r^{*}(t)=\frac{I_{D}(t)}{I_{T}(t)}=r_{0}{ }^{*} \exp \left(-\frac{t}{\theta^{*}}\right)
$$




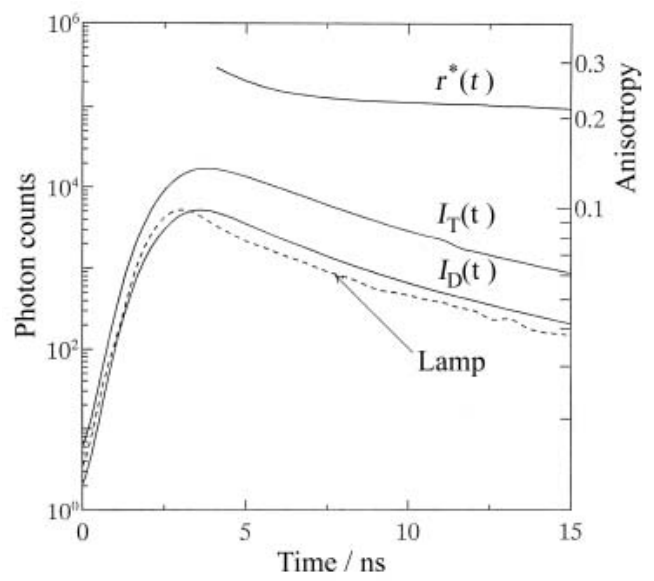

Fig. 5 Time Dependence of Overall Fluorescence Intensity $\left(I_{\mathrm{T}}(t)=I_{\mathrm{VV}}(t)+2 I_{\mathrm{VH}}(t)\right)$, Difference in Fluorescence Intensity between Vertically and Horizontally Polarized Emitted Light $\left(I_{\mathrm{D}}(t)=I_{\mathrm{VV}}(t)-I_{\mathrm{VH}}(t)\right)$ and Time Resolved Fluorescence Anisotropy, $r^{*}(t)$, for $1 \mathrm{CB}$ in Glycerol at $50.6^{\circ} \mathrm{C}$.

where $r_{0}{ }^{*}=\frac{A_{D}}{A_{T}}$. This equation was used for the estimation of a rotational correlation time, $\theta^{*}$. $\theta^{*}$ is related to a molecular volume, $v$, and viscosity, $\eta$, as follows:

$$
\frac{1}{\theta^{*}}=\frac{k_{B} T}{v \eta}
$$

Using the values of $\theta^{*}, k_{\mathrm{B}} T$ and $\eta$, we are able to obtain the molecular volume, $v$, and radius, $a$, assuming a rotational rigid sphere for the $n \mathrm{CB}$ molecules. The values of $\theta^{*}$ for $1 \mathrm{CB}$ and for $6 \mathrm{CB}$ are listed in Tables 3 and 4 , respectively. As can be seen from these Tables, the error for $\theta^{*}$

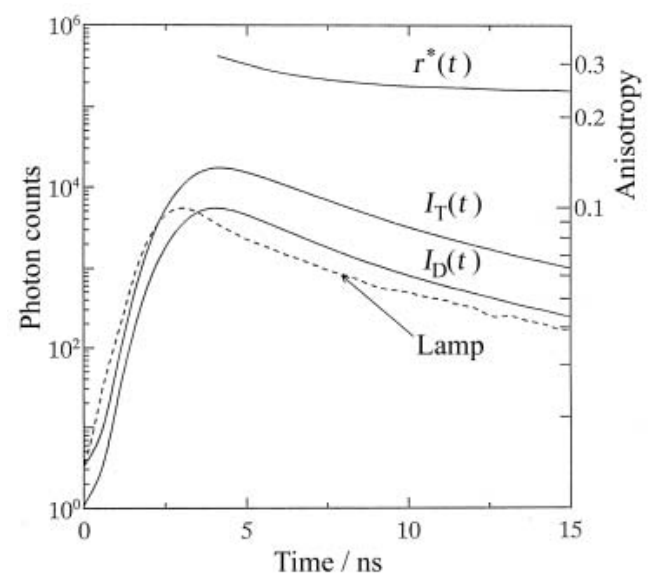

Fig. 6 Time Dependence of Overall Fluorescence Intensity $\left(I_{\mathrm{T}}(t)=I_{\mathrm{VV}}(t)+2 I_{\mathrm{VH}}(t)\right)$, Difference in Fluorescence Intensity between Vertically and Horizontally Polarized Emitted Light $\left(I_{\mathrm{D}}(t)=I_{\mathrm{VV}}(t)-I_{\mathrm{VH}}(t)\right)$ and Time Resolved Fluorescence Anisotropy, $r^{*}(t)$, for $6 \mathrm{CB}$ in Glycerol at $50.9^{\circ} \mathrm{C}$.

decreases with the increase in temperature, and hence, the values of $\theta^{*}$ become considerably reliable at high temperature region. The temperature dependence of the $\theta^{*}$ values for $1 \mathrm{CB}$ and $6 \mathrm{CB}$ indicates that the rotational diffusions for these compounds increase with increasing temperature.

Tables 3 and 4 also present the values of $v$ and $a$ derived from $\theta^{*}$. In order to make the molecular radius profiles more clear, the obtained radii are plotted against temperature as shown in Fig. 7. The each radius versus temperature profile does not simply obey the smooth viscosity change associated with the temperature rise. Namely, there exist three stages: the first stage is below $10^{\circ} \mathrm{C}$; the second one, between $10-30^{\circ} \mathrm{C}$ for $1 \mathrm{CB}$ and $10-40^{\circ} \mathrm{C}$ for $6 \mathrm{CB}$; the third one, above $30^{\circ} \mathrm{C}$ for $1 \mathrm{CB}$ and $40^{\circ} \mathrm{C}$ for $6 \mathrm{CB}$. In the

Table 3 Rotational Correlation Time $\theta^{*}$, Rotational Effective Molecular Volume, $v$, and Spherical Radius, $a$, for 1CB in Glycerol at Various Temperatures Obtained by Assuming Rigid Spherical Model.

\begin{tabular}{|c|c|c|c|c|}
\hline Temperature $/{ }^{\circ} \mathrm{C}$ & $\eta / \mathrm{Pa} \mathrm{s}^{a}$ & $\theta^{* / \mathrm{ns}}$ & volume, $v / 10^{-30} \mathrm{~m}^{3}$ & radius, $a / 10^{-10} \mathrm{~m}$ \\
\hline 3.4 & 8.1237 & $21.4 \pm 18$ & $10.1 \pm 8.3$ & $1.34 \pm 0.36$ \\
\hline 10.1 & 3.8554 & $10.8 \pm 6.9$ & $11.0 \pm 9.1$ & $1.38 \pm 0.37$ \\
\hline 20.3 & 1.3833 & $16.1 \pm 8.7$ & $47.2 \pm 25.5$ & $2.24 \pm 0.40$ \\
\hline 30.4 & 0.5791 & $11.5 \pm 5.6$ & $83.2 \pm 41.0$ & $2.71 \pm 0.44$ \\
\hline 40.7 & 0.2716 & $4.57 \pm 2.5$ & $72.9 \pm 40.1$ & $2.59 \pm 0.47$ \\
\hline 50.6 & 0.1436 & $2.54 \pm 1.4$ & $79.1 \pm 42.2$ & $2.66 \pm 0.47$ \\
\hline 60.8 & 0.0793 & $1.43 \pm 0.78$ & $83.1 \pm 44.8$ & $2.71 \pm 0.48$ \\
\hline
\end{tabular}

${ }^{a}$ values interpolated from the reference data ${ }^{9)}$ 
Table 4 Rotational Correlation Time $\theta^{*}$, Rotational Effective Molecular Volume, $v$, and Spherical Radius, $a$, for $6 \mathrm{CB}$ in Glycerol at Various Temperatures Obtained by Assuming Rigid Spherical Model.

\begin{tabular}{|c|c|c|c|c|}
\hline Temperature $/{ }^{\circ} \mathrm{C}$ & $\eta / \mathrm{Pa} \mathrm{s}^{a}$ & $\theta^{*} / \mathrm{ns}$ & volume, $v / 10^{-30} \mathrm{~m}^{3}$ & radius, $a / 10^{-10} \mathrm{~m}$ \\
\hline 1.7 & 9.8891 & $58.3 \pm 36$ & $22.4 \pm 14.1$ & $1.75 \pm 0.36$ \\
\hline 9.9 & 3.9392 & $25.8 \pm 17$ & $25.6 \pm 17.1$ & $1.83 \pm 0.40$ \\
\hline 30.7 & 0.5655 & $9.27 \pm 5.2$ & $68.8 \pm 38.5$ & $2.54 \pm 0.47$ \\
\hline 39.9 & 0.2869 & $14.1 \pm 4.7$ & $212.4 \pm 70.8$ & $3.70 \pm 0.41$ \\
\hline 49.9 & 0.1499 & $5.37 \pm 2.0$ & $159.8 \pm 60.3$ & $3.37 \pm 0.42$ \\
\hline 60.2 & 0.0820 & $3.67 \pm 1.3$ & $205.9 \pm 72.7$ & $3.66 \pm 0.43$ \\
\hline
\end{tabular}

${ }^{a}$ values interpolated from the reference data ${ }^{9)}$

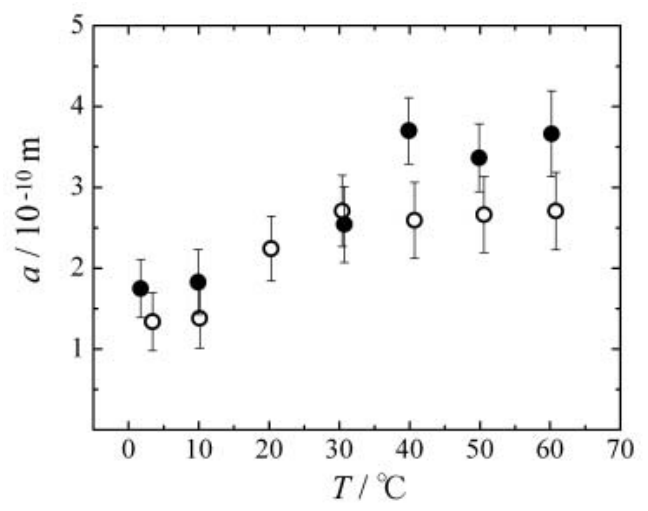

Fig. 7 Rotational Spherical Radius, $a$, for $1 \mathrm{CB}$ and $6 \mathrm{CB}$ in Glycerol at Various Temperatures.

Open circles denote $1 \mathrm{CB}$ and closed circles, $6 \mathrm{CB}$, respectively.

low temperature region (the first stage), the rigid sphere radii are almost constant and average at $1.3 \times 10^{-10} \mathrm{~m}$ for $1 \mathrm{CB}$ and $1.8 \times 10^{-10} \mathrm{~m}$ for $6 \mathrm{CB}$, whereas in high temperature region (the third stage: $1 \mathrm{CB}, 30-60^{\circ} \mathrm{C}$; $6 \mathrm{CB}, 40-60^{\circ} \mathrm{C}$ ), larger constant radii are obtained; i.e., $2.7 \times 10^{-10} \mathrm{~m}$ for $1 \mathrm{CB}$ and $3.6 \times 10^{-10} \mathrm{~m}$ for $6 \mathrm{CB}$. It is noted that the values obtained in the high temperature region are in good agreement with those obtained by using steady-state exciting light, $2.9 \times 10^{-10} \mathrm{~m}(1 \mathrm{CB})$ and $3.4 \times 10^{-10} \mathrm{~m}(6 \mathrm{CB})$, respectively. This indicates that the rigid-sphere model is sufficiently applicable to the rotating $n \mathrm{CB}$ molecules regardless of the length of alkyl-chain attached to cyanobiphenyl part in the high-temperature region.

The increase in radius of rotational diffusion in the intermediate temperature region (the second stage) suggests that the rotational movement changes in this temperature region. In the case of cyanobiphenyl molecules, the rotation about the axes other than the long axis of cyanobiphenyl part play a dominant role for the decay of fluorescence anisotropy, $\bar{r}$. It is noted that the tempera- ture of intermediate region is close to the phase-transition temperature (the phase-transition temperature between the nematic liquid-crystal and isotropic liquid for $6 \mathrm{CB}$ is ca. $\left.29^{\circ} \mathrm{C}\right)^{2}$, however, it is not likely that the rotational movements of $n \mathrm{CB}$ are specifically changed across the intermediate temperature region. Therefore, the relatively steep increase in their radii should be attributable to the enhancement of rotational fluctuations of $n \mathrm{CB}$ molecules, which lead to spherical-rigid rotation. Remarkable increase of a radius observed in $6 \mathrm{CB}$ rather than $1 \mathrm{CB}$ implies that the movements of hexyl-chain are much more enhanced in high temperature, and effectively reflected to the increase in radius of more randomized rotational diffusion.

\section{CONCLUSION}

The cyanobiphenyl part in 4- $n$-alkyl-4'-cyanobiphenyl molecule shows intense absorption due to the $\left(\pi, \pi^{*}\right)$ transition in the ultraviolet region and emits a very strong fluorescence in the visible region. Absorption and fluorescence spectra, fluorescence lifetimes, and steady-state and time-resolved fluorescence anisotropies were measured for 4-methyl-4'-cynanobiphenyl (1CB) and 4-hexyl-4'cynanobiphenyl (6CB) in glycerol at various temperatures. The wavenumbers and intensities of the absorption and emission bands for $1 \mathrm{CB}$ and $6 \mathrm{CB}$ were almost equal to each other. The fluorescence lifetimes for $1 \mathrm{CB}$ and $6 \mathrm{CB}$ were about $1.0 \mathrm{~ns}$ and did not depend on temperature. Thus, the cyanobiphenyl part in $n \mathrm{CB}$ molecule has own property which is not affected by the chain length of the alkyl group. Time-resolved fluorescence anisotropies indicated that the molecules of $1 \mathrm{CB}$ rotate more rapidly than those of $6 \mathrm{CB}$ in glycerol. The rigid-sphere radii for $1 \mathrm{CB}$ and $6 \mathrm{CB}$ obtained by using the pulsed exciting light were evaluated as $1.3 \times$ $10^{-10} \mathrm{~m}(1 \mathrm{CB})$ and $1.8 \times 10^{-10} \mathrm{~m}(6 \mathrm{CB})$ in the low temperature region $\left(2-10^{\circ} \mathrm{C}\right)$, whereas $2.7 \times 10^{-10} \mathrm{~m}(1 \mathrm{CB})$ and $3.6 \times$ 
$10^{-10} \mathrm{~m}(6 \mathrm{CB})$ were obtained in the high-temperature region $\left(1 \mathrm{CB}, 30-60^{\circ} \mathrm{C} ; 6 \mathrm{CB}, 40-60^{\circ} \mathrm{C}\right)$, which were in good agreement with those obtained from the Perrin-Weber plots, $2.9 \times 10^{-10} \mathrm{~m}$ for $1 \mathrm{CB}$ and $3.4 \times 10^{-10} \mathrm{~m}$ for $6 \mathrm{CB}$, respectively. From these results, it is concluded that the rigid-sphere model is acceptable for the rotating 4-metyl-4'cyanobiphenyl and even for 4-hexyl-4'-cyanobiphenyl. An increase in a rotational radius across the intermediate temperature region was notably observed in $6 \mathrm{CB}$ rather than 1CB. The movements of hexyl-chain effectively affect the enhancement of rotational fluctuations and yields increase in radius of rotational diffusion. The relatively large increase in radii attributable to the enhancement of vigorous movements of peripheral alkyl-chain in liquidcrystal molecules is important for the phase transition from liquid crystal to isotropic liquid of 4-alkyl-4'cyanobiphenyls, hence, the changing to less vigorous movements of the peripheral alkyl-chain is thought enough to contribute to the liquid-crystal formation of $6 \mathrm{CB}$ molecules.

\section{References}

1. Lydon, J.E.; Coakley, C.J. Structural study of the smectic mesophases of two biphenyl compounds and an X- ray investigation of the miscibility criterion. J. de Phys. 36, 45-48 (1975).

2. Leadbetter, A.J.; Richardson, R.M.; Colling, C.N. Structure of a number of nematogens. J. de Phys. 36, 37-43 (1975).

3. Naito, A.; Nakatani, H.; Imanari, M.; Akasaka, K. Statecorrelated two-dimensional NMR spectroscopy. $J$. Magn. Reson. 87, 429-432 (1990).

4. Toriumi, H. One- and two-dimensional FTIR timeresolved spectroscopy of liquid crystals. Molecular Crystals and Liquid Crystals A 262, 1659-1666 (1995).

5. Toriumi, H. One- and two-dimensional FT-IR time resolved spectroscopy. Bunko Kenkyu 42, 215-228 (1993).

6. Azumi, T.; McGlynn, S.P. Polarization of the Luminescence of Phenanthrene J. Chem. Phys. 37, 2413-2420 (1962).

7. Lakowicz, J.R. Principles of Fluorescence Spectroscopy. 2nd edn. Kluwer Academic/Prenum Publishers. New York. pp. 291-306 (1999).

8. Fujita, I.; Kobayashi, H. Luminescence polarization of the tris (2,2'-bipyridine) ruthenium (II) complex. Inorg. Chem. 12, 2758-2764 (1973).

9. Kagakubinran Kisohen 4th edn. (Chemical Society of Japan ed.) Maruzen, Tokyo, II-38 (1993). 